\title{
Thin Films of Zirconia-Phosphate Glasses Deposited by an Aerosol CVD Process
}

\author{
J.L. Deschanvres, J.M. Vaca and J.C. Joubert \\ Laboratoire des Matériaux et du Génie Physique, Ecole Nationale Supérieure de Physique de Grenoble, \\ Domaine Universitaire, BP. 46, 38402 St Martin d'Hères, France
}

\begin{abstract}
The polycrystalline state of the $\mathrm{ZrO}_{2}$ films was an disadvantage for some specific protective coating applications. To resolve this fact we proposed to obtain an amorphous thin film by addition of $\mathrm{P}_{2} \mathrm{O}_{5}$, which will act as glass formator agent. With an aerosol CVD process by using zirconium acetylacetonate and triphenyl phosphate dissolved in a mixture of acetylacetone and benzyl alcohol, we achieved to deposit mixed $\mathrm{P}_{2} \mathrm{O}_{5}-\mathrm{ZrO}_{2}$ films between $480^{\circ} \mathrm{C}$ and $600^{\circ} \mathrm{C}$. The $\mathrm{P}_{2} \mathrm{O}_{5}$ content varied from $0 \%$ up to $60 \%$. By measuring systematically the composition of the film we have noticed the influence on the composition of the films, on the one hand of the hygrometric degree of the carrier gas and on the other hand of the temperature used for the dissolution of the organometallic precursors in the solvent. The highest the dissolution temperature was, the most the phosphorus content was. After an annealing at $500^{\circ} \mathrm{C}$ during one hour, the films exhibited by Xray diffraction analysis an amorphous structure and a very good transparency. More over the evolution of the I.R. spectra between $1200 \mathrm{~cm}^{-1}$ and $900 \mathrm{~cm}^{-1}$ and arround $400 \mathrm{~cm}^{-1}$ are discussed in function of the composition of the films.
\end{abstract}

\section{INTRODUCTION}

Due to their high chemical corrosion resistance $\mathrm{ZrO}_{2}$ thin films are an attractive solution for protective coating applications. But the polycrystalline state of the $\mathrm{ZrO}_{2}$ films is an important disadvantage due to the grain boundaries. To resolve this fact we proposed to obtain an amorphous thin film by addition of $\mathrm{P}_{2} \mathrm{O}_{5}$, which will act as glass formator agent. To reach this purpose in our laboratory we have developed an aerosol CVD process and this paper reports the deposition conditions to obtain mixed amorphous $\mathrm{P}_{2} \mathrm{O}_{5}-$ $\mathrm{ZrO}_{2}$ films.

\section{EXPERIMENTAL DETAILS}

\subsection{Deposition process}

The deposition process has been reported elsewhere in connection with the production of thin films of several kinds of oxides [1,2]. The process is based on the pyrolysis on a heated substrate of an aerosol produced by ultrasonic spraying of a solution. A flat piezoelectric transducer, located at the bottom of a glass vessel, generated an ultrasonic beam in a solution containing the reactants of the materials to be deposited.At a frequency arround $800 \mathrm{kHz}$ a geyser occured at the surface of the solution and ultrafine droplets $(4-10 \mu \mathrm{m})$ are produced above the surface of the liquid and are conveyed by a carrier gas close to the heated substrate. A pyrolysis reaction occurs on the substrate. owing to the very narrow spectrum of the size of the droplets, a heterogenous reaction occurs at the gas/substrate interface over a wide temperature range, leading to the CVD process. The precursors are selected according to the need for high vapour pressure at low temperature.

Deposits were obtained on monocrystalline (100) silicon wafer or on glass substrate and the deposition temperature ranged from $480^{\circ} \mathrm{C}$ to $600^{\circ} \mathrm{C}$ with a deposition rate between $0,1 \mu \mathrm{m}$ and $2 \mu \mathrm{m}$ per hour. For the zirconium and the phosphorus, the studied precursors were respectively the $\mathrm{Zr}$ terbutoxide or the $\mathrm{Zr}$ 
acetylacetonate and the tributyl or the triphenyl phosphate. Various solvents like acetylacetone (AcAc), butanol $(\mathrm{BuOH})$ or benzyl alcohol $(\mathrm{BzAl})$ were used for the preparation of the starting solution.

\subsection{Characterisations}

$\mathrm{X}$-ray diffraction patterns were obtained using a Siemens diffractometer with FeK $\alpha$ monochromated radiation. The measurements were made with a fixed tube incident angle of $2^{\circ}$, a fixed sample and only with a scan of the detector ( $2 \theta$ scan ). Because of this type of measurement the silicon wafer did not exhibite diffraction lines. The composition of the films has been measured by electron microprobe analysis by a wavelength dispersive system, performed with a CAMECA SX50 apparatus. The measurements of the $\mathrm{K}$ ratio for the $\mathrm{Si} \mathrm{K} \alpha, \mathrm{O} \mathrm{K} \alpha, \mathrm{P} \mathrm{K} \alpha$ and $\mathrm{Zr} \mathrm{L} \alpha$ peaks, obtained at different high acceleration voltages, were analysed with a special thin films analysis program [3], named Strata and edited by the french society SAMX. With this program the composition and the mass thickness of the deposited films can be determined. The infrared transmittance of the films deposited on silicon wafer was studied with a Bio-Rad infrared Fourier Transform apparatus between $200 \mathrm{~cm}^{-1}$ and $1500 \mathrm{~cm}^{-1}$.

\section{RESULTS}

\subsection{Choice of the solvent and of the precursors}

As first step for this work we have studied the deposition conditions for pure $\mathrm{ZrO}_{2}$ films by using two different zirconium precursors: zirconium 2,4 pentanedionate and zirconium terbutoxide. The dissolution of each precursor have been checked respectively in butanol, acetylacetone, benzyl alcohol and in each mixture (for the mixture of solvents the volume ratio always was $50 \%-50 \%$ ). The dissolution of the zirconium butoxide is easely obtained in each solvent, but it exhibited a too high chemical reactivity with the moisture. So we choose to use only the zirconium acetylacetonate which price is moreover very much cheaper.

\begin{tabular}{|c|c|c|c|c|c|c|}
\hline solvent & AcAc & BuOH & BzAl & $\begin{array}{c}\text { AcAc/BuOH } \\
50 \%-50 \%\end{array}$ & $\begin{array}{c}\text { AcAc/BzAl } \\
50 \%-50 \%\end{array}$ & $\begin{array}{c}\text { BzAl/BuOH } \\
50 \%-50 \%\end{array}$ \\
\hline solubility & no & no & very good & poor & very good & very good \\
\hline deposition & - & - & no & yes & yes & yes \\
\hline
\end{tabular}

Table I :Results of the dissolution and deposition test of the zirconium acetylacetonate in different solvents

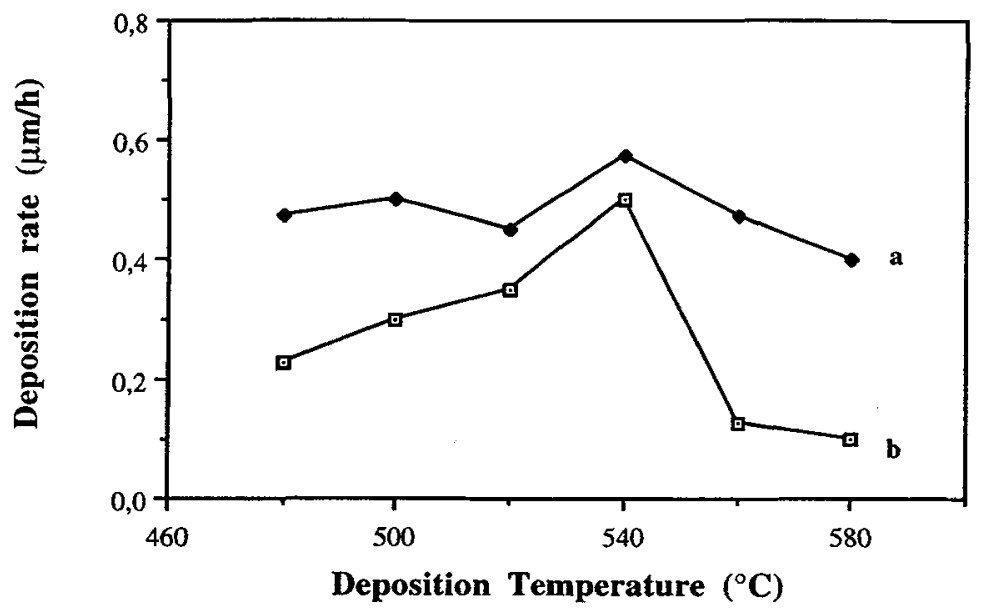

Figure 1 : The deposition rate of $\mathrm{ZrO}_{2}$ films obtained with zirconium acetylacetonate dissolved in a mixture of (a) acetylacetone and benzyl alcohol and of (b) acetylacetone and butanol. 
The table $\mathrm{I}$ resumed the results of the dissolution and deposition tests. In the benzyl alcohol the dissolution is obtained very quickly until $0,2 \mathrm{~mol} / \mathrm{l}$, but with this solution no films could be deposited. In contrary by using mixed solvent it was possible to obtain transparent and adherent $\mathrm{ZrO}_{2}$ thin films on silicon wafer or on glass substrate. As schown in figure 1, the highest deposition rates are obtained with the mixture of acetylacetone and benzyl alcohol with a maximum at $540 \mathrm{C}^{\circ}$.

For the phosphorus precursors, the tributyl or the triphenyl phosphate, the dissolution in the different solvents is easely obtained. Because of the tributyl phosphate led to the deposition of completely black films at temperature above $550^{\circ} \mathrm{C}$, due to an important carbon incorporation, for the deposition of the mixed $\mathrm{P}_{2} \mathrm{O}_{5}-\mathrm{ZrO}_{2}$ films we have used the triphenyl phosphate and the zirconium acetylacetonate dissolved in the mixture of acetylacetone and benzyl alcohol with the same volume proportion (50\%-50\%).

\subsection{Composition of the films}

We have systematically studied the composition of the deposited films with regard to the deposition parameters (temperature, composition of the starting solution,...). In particular we have noticed the influence on the composition of the films, on the one hand of the hygrometric degree of the carrier gas and on the other hand of the temperature used for the dissolution of the organometallic precursors in the solvent. In fact the dissolution of the precursors is obtained by stirring and heating the solution for one hour at different temperature $\left(70^{\circ} \mathrm{C}, 90^{\circ} \mathrm{C}, 120^{\circ} \mathrm{C}\right)$ with a refluxing device. As schown on figure 2 , the highest the dissolution temperature was, the most important the phosphorus content was and the most the phosphorus content increased with the deposition temperature. This effect is also associated with the increase of the carbon incorporation, which is revealed by a light brown color of the films. Moreover the different dissolution temperature corresponded to a change of the color of the starting solution, which was light yellow after the heating at $70^{\circ} \mathrm{C}$ and which became between orange and brown after the heating at $120^{\circ} \mathrm{C}$.

To study the influence of the hygrometric degree of the carrier gas, we have used either a pure gas mixture of $\mathrm{N}_{2}$ and $\mathrm{O}_{2}(80 \%-20 \%)$ with a hygrometric degree of $0,004 \mathrm{gH}_{2} \mathrm{O} / \mathrm{m}^{3}$ or purified compressed air with a hygrometric degree of $0,5 \mathrm{~g} \mathrm{H}_{2} \mathrm{O} / \mathrm{m}^{3}$ or $6 \mathrm{~g}_{2} \mathrm{O} / \mathrm{m}^{3}$ obtained by a refrigerating device. As schown on figure 3, the phosphorus content increased when the hygrometric degree went up and the higher the deposition temperature was, the greater this effect was. We don't yet understand this results, but they were reproducible in the different deposition conditions.Furthermore the deposition rate depended only slightly on the dissolution temperature and on the hygrometric degree of the carrier gas (figures 4 and 5). For the deposition of the films we use solutions with a total concentration of $0,4 \mathrm{~mol} / \mathrm{l}$ and to control the composition of the deposited films, we adjust the dissolution and the deposition temperature and the composition of the starting solution.

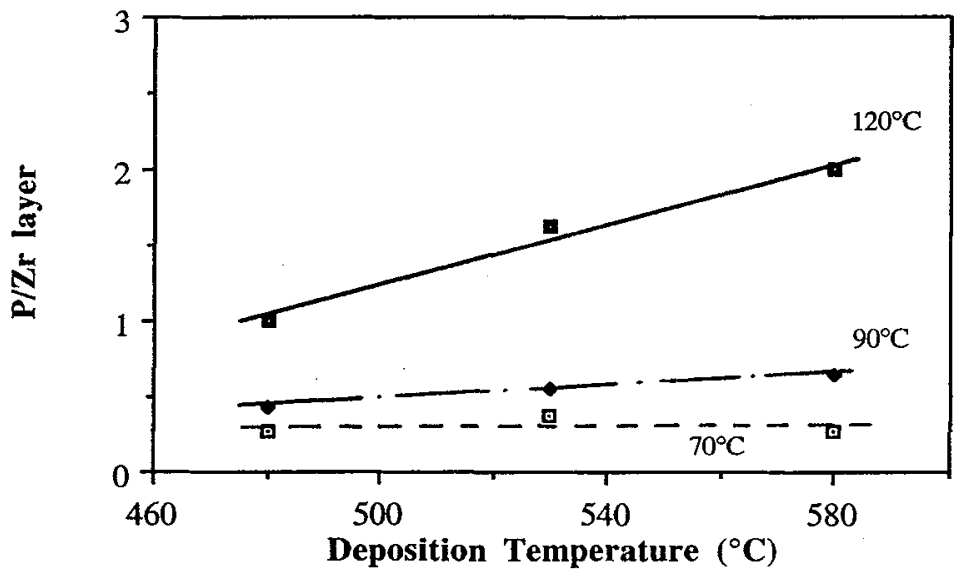

Figure 2 : Evolution of the atomic composition ratio of the layer ( $\mathrm{P} / \mathrm{Zr}$ ratio by number with an accuracy of $10 \%$ ) versus the deposition temperature for different dissolution temperatures used for the preparation of the starting solution. The atomic composition ratio of the solution ( $\mathrm{P} / \mathrm{Zr}$ by number) was four with a total concentration of $0,4 \mathrm{~mol} /$. 


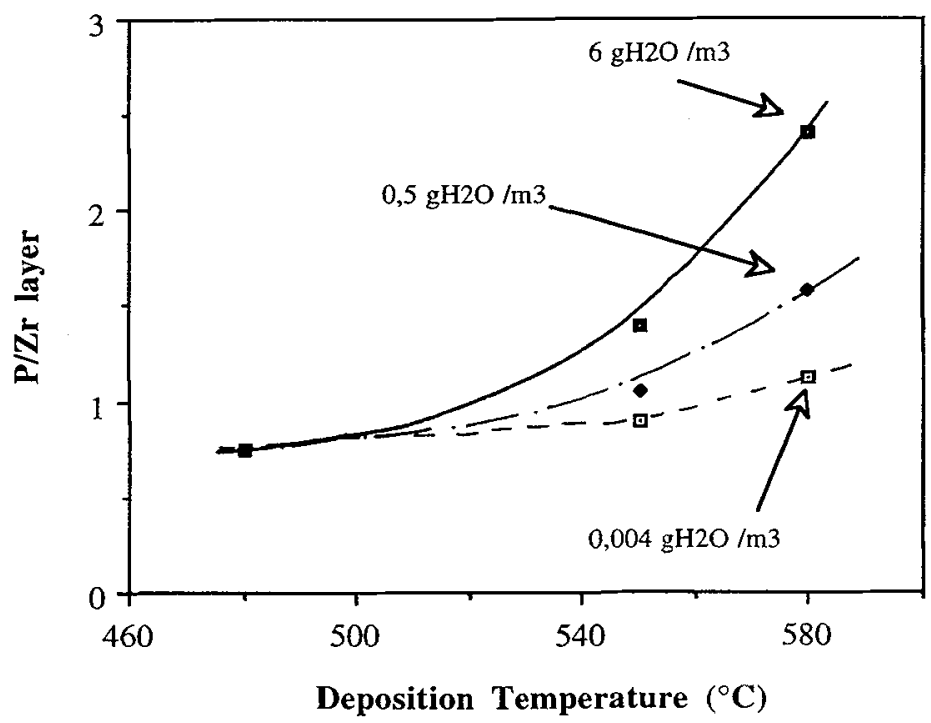

Figure 3: Evolution of the atomic composition ratio of the layer versus the deposition temperature for different hygrometric degrees of the carrier gas. The atomic composition ratio $\mathrm{P} / \mathrm{Zr}$ of the solution was four and the dissolution temperature was $120^{\circ} \mathrm{C}$.

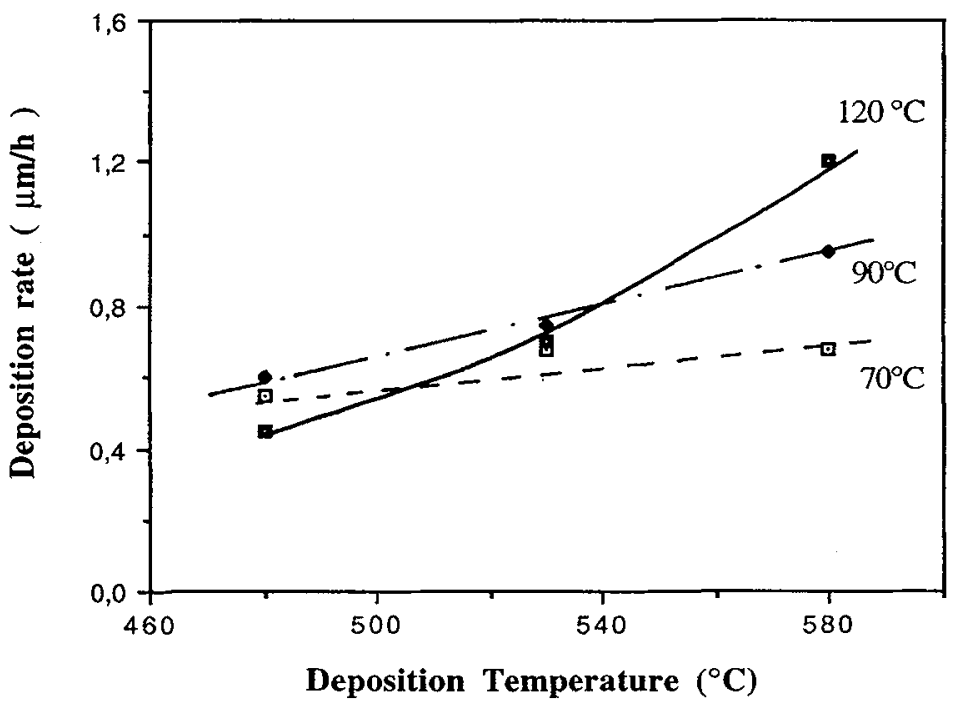

Figure 4 : Deposition rate versus the deposition temperature for different dissolution temperatures. The atomic composition ratio $\mathrm{P} / \mathrm{Zr}$ of the solution was four . 


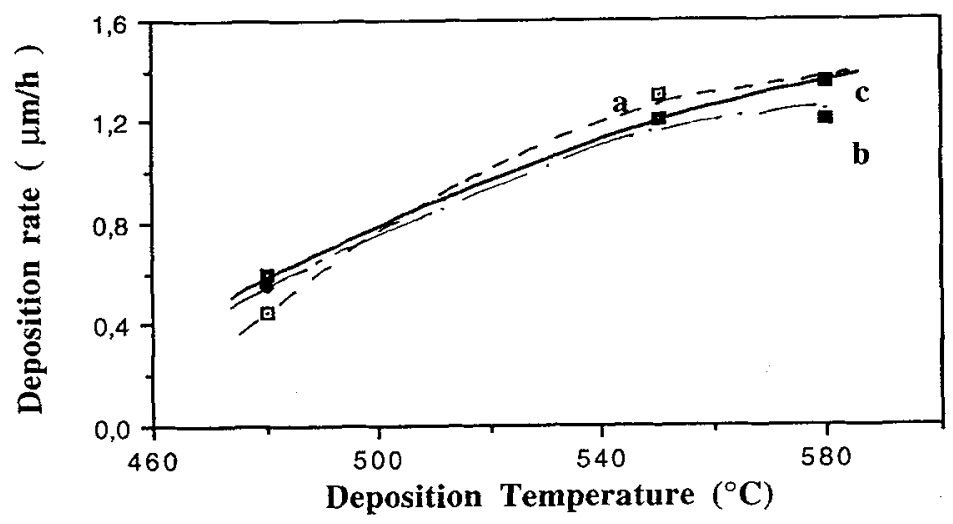

Figure 5 : Deposition rate versus the deposition temperature for different hygrometric degrees of the carrier gas (a) $6 \mathrm{gH}_{2} \mathrm{O} / \mathrm{m}^{3}$, (b) $0,004 \mathrm{gH}_{2} \mathrm{O} / \mathrm{m}^{3}$ and (c) $0,5 \mathrm{gH}_{2} \mathrm{O} / \mathrm{m}^{3}$. The atomic composition ratio $\mathrm{P} / \mathrm{Zr}$ of the solution was four and the dissolution temperature was $120^{\circ} \mathrm{C}$.

\subsection{Properties of the deposited films}

After an annealing at $500^{\circ} \mathrm{C}$ for one hour, the mixed films exhibited a very good optical transparency due to the entire combustion of the carbon. As shown on figure 6 , the pure $\mathrm{ZrO}_{2}$ film revealed by X-ray diffraction analysis a cubic polycristalline structure. The mixed films were amorphous even for a low $\mathrm{P}_{2} \mathrm{O}_{5}$ content $(11 \%)$ and after an annealing at $500^{\circ} \mathrm{C}$ or at $600^{\circ} \mathrm{C}$ for one hour. After the annealing at $500^{\circ} \mathrm{C}$, the films deposited on glass substrate exhibited a transparency higher than $95 \%$ in the visible part of the spectrum, which revealed a complete combustion of the incorporated carbon.

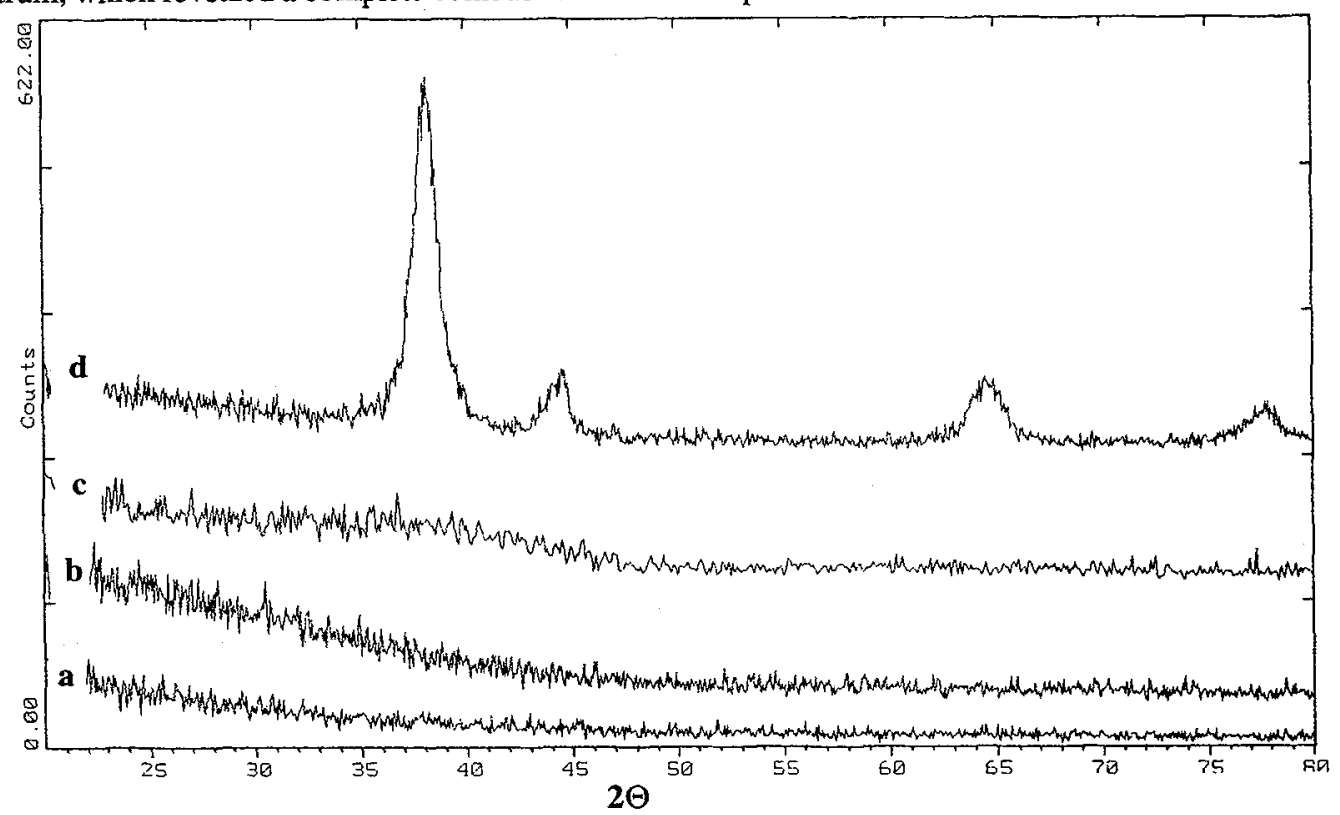

Figure 6: Detector scan X-ray diffraction patterns obtained for different samples after an annealing at $500^{\circ} \mathrm{C}$ for 1 hour:

a - silicon wafer

b - mixed $\mathrm{P}_{2} \mathrm{O}_{5}-\mathrm{ZrO}_{2}$ thin film with $\mathrm{P}_{2} \mathrm{O}_{5} \%=54 \%$ or $\mathrm{P} / \mathrm{Zr}=2,35$

c - mixed $\mathrm{P}_{2} \mathrm{O}_{5}-\mathrm{ZrO}_{2}$ thin film with $\mathrm{P}_{2} \mathrm{O}_{5} \%=11 \%$ or $\mathrm{P} / \mathrm{Zr}=0,26$

$\mathrm{d}$ - pure $\mathrm{ZrO}_{2}$ thin film 
The infrared spectra of the samples between $1500 \mathrm{~cm}^{-1}$ and $200 \mathrm{~cm}^{-1}$ allowed us to study this amorphous films. The figure 7 shows the infrared transmittance spectra of a pure $\mathrm{ZrO}_{2}$ film and of mixed films with different $\mathrm{P}_{2} \mathrm{O}_{5}$ content ( $11 \%, 38 \%, 54 \%$ ). When the $\mathrm{P}_{2} \mathrm{O}_{5}$ content increase, a wide absorption band appears between $900 \mathrm{~cm}^{-1}$ and $1300 \mathrm{~cm}^{-1}$. This band may be deconvolve into five peak, which were centered respectively at $955,1025,1085,1140$ and $1240 \mathrm{~cm}^{-1}$. Because of the different measured films have not the same thickness, the analysis of the different spectra can not be made directly by comparing the intensity of each peak, but only by noticing the evolution of the relative peak intensity ratio. According to the studies of Wong [4], Bridge [5] or Chowdary [6], the peak at $1240 \mathrm{~cm}^{-1}$ can be assigned to a stretching vibration of the $\mathrm{P}=\mathrm{O}$ bond. It is reasonable to notice that this vibration appears only for high $\mathrm{P}_{2} \mathrm{O}_{5}$ content . Because of the relative absorption intensity ratio between the peak at 955 and $1140 \mathrm{~cm}^{-1}$ is quite constant for the different mixed samples, this peaks can be assigned to the bond stretching motions of the P-O-P unit according to Wong and to the study of Chang [7] which reported calculated vibrational spectrum of $\mathrm{P}_{2} \mathrm{O}_{5}$ glass. The two other peaks at 1025 and $1085 \mathrm{~cm}^{-1}$ may be corresponded at stretching vibrations of the $\mathrm{PO}_{3}$ unit or of the $\mathrm{P}-\mathrm{O}-\mathrm{Zr}$ bond as tentative assignement .
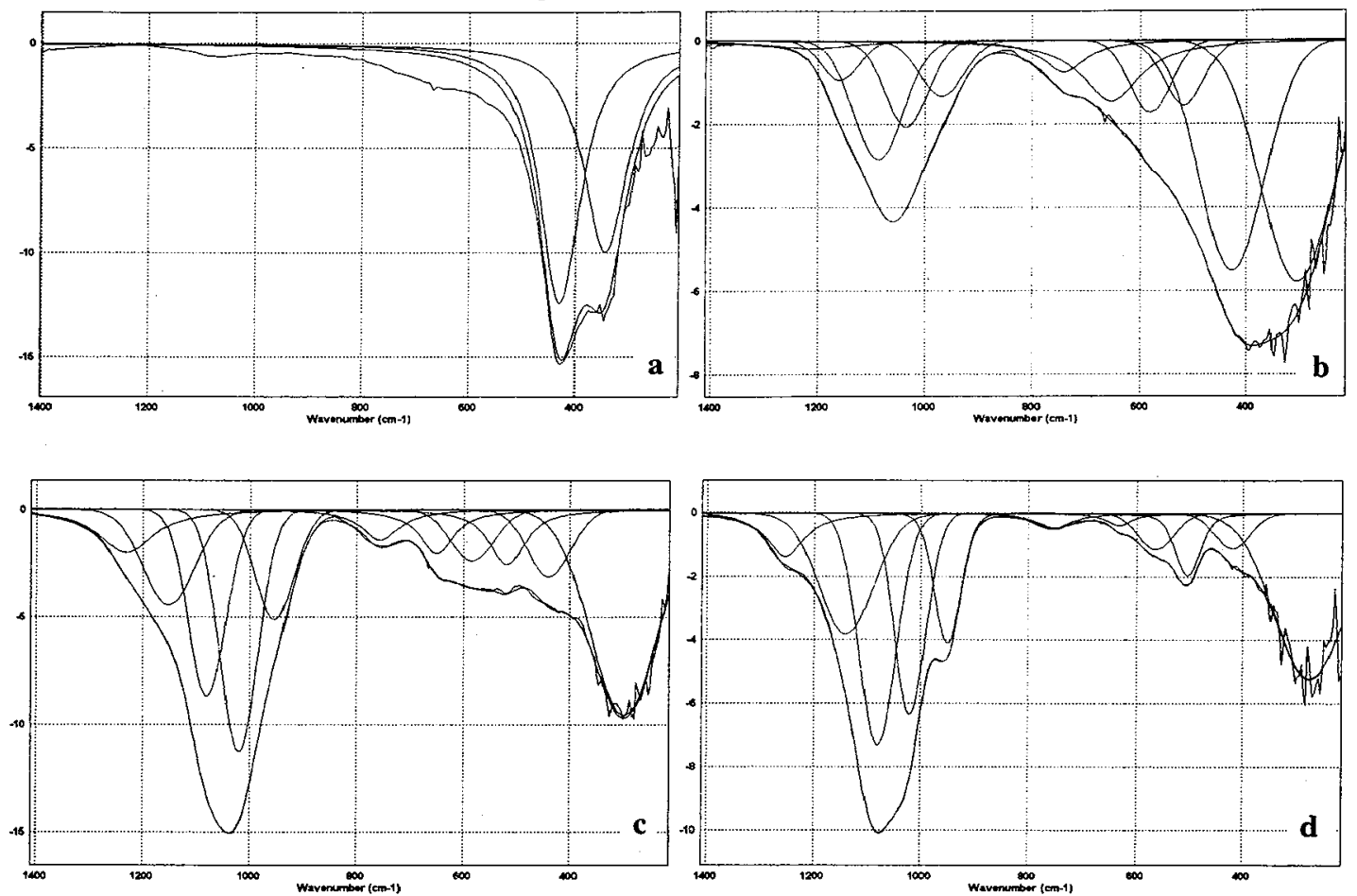

Figure 7 : Transmittance Infrared spectra after $\mathrm{Si}$ wafer substraction and curve fitting results of different deposited films after an annealing at $500^{\circ} \mathrm{C}$ for 1 hour;

$$
\begin{aligned}
& \text { a - pure } \mathrm{ZrO}_{2} \text { thin film } \\
& \text { b - mixed } \mathrm{P}_{2} \mathrm{O}_{5}-\mathrm{ZrO}_{2} \text { thin film with } \mathrm{P}_{2} \mathrm{O}_{5} \%=11 \% \text { or } \mathrm{P} / \mathrm{Zr}=0,26 \\
& \text { c - mixed } \mathrm{P}_{2} \mathrm{O}_{5}-\mathrm{ZrO}_{2} \text { thin film with } \mathrm{P}_{2} \mathrm{O}_{5} \%=38 \% \text { or } \mathrm{P} / \mathrm{Zr}=1,25 \\
& \text { d - mixed } \mathrm{P}_{2} \mathrm{O}_{5}-\mathrm{ZrO}_{2} \text { thin film with } \mathrm{P}_{2} \mathrm{O}_{5} \%=54 \% \text { or } \mathrm{P} / \mathrm{Zr}=2,35
\end{aligned}
$$

\section{CONCLUSION}

The deposition of amorphous mixed $\mathrm{P}_{2} \mathrm{O}_{5}-\mathrm{ZrO}_{2}$ films have been achieved by using an aerosol CVD process. Highly transparent films with various $\mathrm{P}_{2} \mathrm{O}_{5}$ content $(0 \%$ up to $60 \%)$ have been deposited at temperature between $480^{\circ} \mathrm{C}$ and $600^{\circ} \mathrm{C}$ by using a starting solution of zirconium acetylacetonate and triphenyl phosphate dissolved in a mixture of acetylacetone and benzyl alcohol. The deposition rate ranged from $0,1 \mu \mathrm{m}$ to $2 \mu \mathrm{m}$ per hour and the X-ray diffraction analysis revealed an amorphous structure even for a low $\mathrm{P}_{2} \mathrm{O}_{5}$ content. 


\section{References}

[1] Deschanvres J.L. et al., Journal de Physique, C5, Tome 50 (1989) 695-705.

[2] Deschanvres J.L.and Joubert J.C., Journal de Physique IV,Vol 2 (1992) 29-33.

[3] Pouchou J.L. and Pichoir F., La Recherche Aerospatiale, N 5 (1984) 349-367.

[4] Wong J., Journal of Non-Crystalline Solids, 20 (1976) 83-100.

[5] Bridge B. and Patel N.D., Journal of Non-Crystalline Solids, 91 (1987) 27 - 42.

[6] Chowdari B.V.R. et al.,Journal of Non-Crystalline Solids, 160 (1993) 73 - 81.

[7] Chang W.B., Jin Z.Z. and Zou X.W., Phys. Lett. A, 159 (1991) 361 - 364. 
